\title{
Meaningfully Engaging Karen Refugee Families in Physical Activity: The Outcomes of A Culturally Specific, Co-Designed Program
}

Téa O'Driscoll ( $\nabla$ tea.odriscoll@vu.edu.au )

Victoria University

Ramón Spaaij

Victoria University

Erika Borkoles

Griffith University

Remco Polman

Queensland University of Technology

\section{Research Article}

Keywords: Active lifestyles, co-design, community program, cultural sensitivity, migrants, physical activity, refugees, sport, wellbeing

Posted Date: November 30th, 2020

DOl: https://doi.org/10.21203/rs.3.rs-111767/v1

License: (c) (i) This work is licensed under a Creative Commons Attribution 4.0 International License. Read Full License 


\section{Abstract}

Background There are numerous health and social benefits of physical activity (PA) participation, yet refugees who have settled into destination countries like Australia are less likely to play sport or exercise, or reach recommended daily PA levels if they do. There may be various correlates of PA which impact on participation, however cultural attributes and the process of cultural adaptation after resettlement, may be a key contributor, impacting on the health of resettlers. This research trialled a community-driven, culturally specific family PA program with Karen refugees settled in Australia. The aims of the program were to encourage participation through a culturally appropriate physical activity setting and provide Karen families with an opportunity to learn to be active together.

Methods The grant-funded program consisted of a two-hour lifestyle educational module and a practical activity session held each week for eight weeks, including a six-month follow-up session post completion. Educational sessions covered relevant health topics, such as healthy eating, and practical activity sessions were tailored to meet Karen people's cultural expectations and needs. All components of the intervention were co-designed with the participants.

Results A total of 36 Karen adults and children varying in ages participated in the program, with an average rate of participation of $81.8 \%$ over eight weeks. The program was evaluated with surveys, interviews, and informal discussions with instructors and participants, as well as ethnographic methods of observation. Participants valued the program that met their needs. After completion of the program they requested to continue with a similar community-based PA program in the future.

Conclusions This culturally appropriate and co-designed PA program effectively engaged Karen people and increased healthy lifestyle behaviours in the group, which they found valuable and meaningful. Future interventions and programs targeting resettled refugees should be co-designed with participants using culturally appropriate approaches.

\section{Background}

The physical, psychological, and social health benefits of physical activity (PA) participation across all populations are well documented [1-8]. However, resettled refugees are less likely to partake in these activities, or attain recommended levels of PA $[9,10]$. This is particularly concerning for governments and civil society organisations working with refugees in destination countries like Australia, who are increasingly aware that such groups may be missing out on fundamental health and social benefits of PA participation. Previous studies have identified various factors affecting PA, and in particular sport participation, for culturally and linguistically diverse (CALD) people such as resettled refugees. These include language barriers, accessibility such as inappropriate sport facilities and lack of knowledge of available opportunities, financial cost, a lack of familiarity and comfort, competing life demands (e.g., work, family duties), and experienced discrimination [11-13]. A systematic review of qualitative studies by Horne and Tierney [14] suggested that South Asian groups residing in the UK and Canada were less likely 
to engage in PA compared to Caucasians, and had increased rates of lifestyle diseases such as coronary heart disease and Type-Il diabetes. Research has also explored the impact of acculturation; a process of individual psychological changes, stress and individual influences upon the adoption or resistance to a different culture's characteristics [15, 16], on PA participation behaviours [17]. In general, and particularly during the process of acculturation, culturally specific constraints, beliefs, and values affect PA participation $[12,13,18]$. In our own research with refugee-background Karen people in Melbourne, Australia, we found that most participants had been significantly active, through sport or some other type of PA, prior to arriving to Australia. However, very few continued with such behaviours post settlement, due in part to cultural differences in the concepts and assigned meanings to sport and PA of Karen and Australian perspectives.

In an evaluation of physical activity services for CALD groups, it was found that albeit services were available, there was limited understanding and awareness of the cultural characteristics of each diverse CALD group [19]. This ultimately impacted on the service provider's capacities to develop PA programs to be accessible, and to address the barriers associated with meaningful participant engagement in their programs. Implementation of supporting services such as childcare and transport assistance, can improve access and engagement with PA programs designed for CALD communities [20].

Ley and Barrio [21] argued that health (including stressors and resources to address them) must be considered and addressed in projects targeting refugees [21]. Also that the health status of refugees, ranging from prevalence of posttraumatic stress disorder (PTSD), depression, anxiety, issues with concentration or motivation, as well as physical health issues, are often not considered [21]. Research has shown that participation in PA can support psychosocial wellbeing, and may assist with recovering from mental illnesses such as depression [22, 23], highlighting the need to focus on engagement in PA for CALD groups. A recent study evaluating experiences of treatment-targeted PA programs for traumaafflicted refugees, found that participants built resilience and showed improvements in both physical and mental health outcomes, whilst the programs provided a break from other daily stressors and gave a sense of recovery [24]. Service providers implementing sport and other PA programs for CALD groups were advised to consider culturally specific characteristics of their target groups and the needs of these participants through collaborative and participatory approaches. Collaborations with participants or key service providers, can assist with developing a greater sense of understanding of the various factors associated with PA participation, such as barriers specific to the group, or access issues [e.g. 19, 25]. In their recent study with Syrian youth in Canada, Robinson, Robinson, Currie and Hall [25] engaged with Syrian community partners, who assisted with culturally appropriate and effective recruitment, as well as providing a deeper level of understanding of the various social systems influencing participation. This led to the development and implementation of a co-created and culturally appropriate youth sports program that increased participants' physical literacy (e.g. motivation, confidence and knowledge) and sense of belonging (e.g. feeling involved and included in their community) [25].

Recognising the need to develop a deep understanding of cultural variables and related concepts of health, sport, and PA, in promoting sport and other PA participation for CALD groups, we conducted two 
independent studies exploring cultural variables in refugee-background Karen people in Australia, that have been documented elsewhere [26]. This work provided us with an opportunity to co-design and implement a community-driven culturally specific PA program, which was based on some of the key findings of those previous studies. This PA program was developed using a community participatory method, whereby the development, structure, and implementation was co-designed with participants, and thus addressed cultural barriers, in order to meet the specific needs of the group. Similar methods including participatory methods [27] and co-creation approaches [28], are perceived to address potential power imbalances between researchers and community members, and create opportunities for reciprocal learning in an endeavour to create sustainable change [29]. However, researchers and public health practitioners often do not utilise co-design approaches from program inception, to design and implement public health interventions [30,31]. Thus, central to the structure of our PA program was community participation and input from conception through to implementation, a focus on cultural collectivism and family values, and a strong commitment to flexibility in planning and implementation, based on evolving community needs and requests.

The PA program was a feasibility study and aimed to investigate whether a culturally tailored PA intervention could effectively engage a group of refugee-background Karen people, and was evaluated for appropriateness and value to the participants. The objectives of the program were threefold: 1 ) encourage participation in PA through a co-designed and culturally appropriate program, 2) provide a platform for families to learn to be active together in a meaningful way, and, 3) introduce a variety of new PA activities for Karen families to try for the first time. These objectives were directly derived from our previous findings and the identification of needs that Karen people expressed. In their view, sport and PA in Australia was foreign and different to the 'Karen version'. The Karen highly value collectivism and tight family bonds (including participating in all activities together), and, the community wanted to try new and unfamiliar PA activities in Australia. The outcome measures relating to these aims were adherence rates and a collection of feedback sources: direct participant, instructor and/or educator feedback, informal discussions, and observational reflection. The study was approved by the University Human Research Ethics Committee.

\section{Methods}

\section{Participants}

Thirty-six participants were registered in the program, with an additional two who were not registered but attended weekly for fun. In total, there were 17 family units comprising of between one to five individuals, with most units consisting of at least one parents and two to three children. Interventions similar to our program that aimed to increase PA participation in culturally diverse communities [e.g. 32, 33] often had larger numbers of participants (e.g. 75-100). Unlike such interventions, our program was specifically tailored for a community within a local area, whereby the focus was to make the program and the community hub participatory, accessible, appropriate, and valuable; rather than increase PA levels. 


\section{Demographics}

Of the registered participants, 24 were female and 12 were male. There were 19 children (17 years old and younger); 8 males and 11 females, with an average age of 9.2 years old, and 17 adults (18 years old and older); four males and 13 females, with an average age of 34 years. All participants were refugeebackground Karen people, who had been in Australia for various lengths of time ranging from 4 months through to being born in Australia. Most of the children were comprehensive or fluent in the English language, whilst all adults (except two) had little to no English language comprehension. The community leader was bilingual, and thus provided interpreting services during the program.

\section{Recruitment}

Participants were recruited through community leaders via verbal and word-of-mouth means, as it was identified as being the most effective and appropriate method for the target group, due to the largely oral and collectivist nature of the group. Information was relayed verbally to community leaders, key community members and local networks and community channels including refugee and migrant service providers, local government, and church groups.

\section{Measurements and data collected}

During the first session and the six-month follow up, measurements for weight, height, hip/waist circumference, and time performing 'the plank' (balancing position performed by resting weight on the tips of the toes and forearms) were collected. Height and weight were used to calculate a Body Mass Index (BMI), and hip and waist measurements were used to calculate waist-to-hip ratios (WHR).

Evaluating changes in these measurements was not an outcome of the program, but rather served as a learning tool and discussion point. These practices are commonplace within the Australian health care system, and it was perceived as important for participants, particularly those who were newly arrived, to be aware of, and feel comfortable with, these measurement procedures. They also complemented the educational modules throughout the intervention, particularly discussions on obesity and Type-II diabetes risk factors. However, individual BMI and WHR measurements were not discussed with participants, nor was the information used to infer any classifications or risk factors for individuals as part of the program. During the first session, facilitators assisted in collecting participant measurements, whilst participants were encouraged to take their own measurements and records for the six-month follow up.

A written evaluation questionnaire (provided in both Karen and English languages) was completed by all participants in the last session. Brief interviews were conducted with willing physical activity instructors either in person, on the phone, or via email, after their involvement in the program. For all sessions, the primary method of data collection was observation and semi-ethnographic forms of documentation and reflection, which were all collated into a weekly journal by the main researcher.

\section{Equipment}


All equipment was purchased from program funding awarded by Medicare Local $(\$ 13,900)$, and consisted of various play-based resources that were purchased from that funding. Ball game and other equipment, such as football goals, volleyball nets, hula hoops, tug of war rope, balance beams, skipping ropes, ten pin bowling sets, grip ball and sack racing bags, were donated post-program to the community hub as a resource for sustaining the PA activities (e.g. via a free to loan basis), and to encourage continued use of the community hub. The portable volleyball net and one ball was donated to the community leader, who organised for it to be stored at the local church that was available and accessible for anyone to use casually. Equipment considerations were given to popular play-based activities that could engage individuals of various ages and skill levels, in a fun and safe way. Graduation certificates and 'stay active packs', consisting of a backpack and various small pieces of active equipment such as skipping ropes and frisbees, were presented to each family unit at the end of the program on 'graduation day'.

\section{Procedure}

A schedule of sessions was co-designed with the community leader and interested participants. Due to the evolving nature of the program, three weeks of sessions were firmly finalised, however, the remaining schedule was flexible and open to changes based on community response. The program was composed of a weekly session held every Saturday afternoon for 2 hours for a period of 8 weeks. Each session comprised of a short group discussion guided by the participants (e.g. questions, requests), a physical activity session (approx. 45-60 minutes), an educational module (approx. 30-40 minutes), followed by free time for healthy snacks and socialising.

\section{Program description}

\section{Physical activities}

The different physical activity sessions included: karate, golf, gymnastics, football and volleyball, and play-based (games). Table 1 outlines the rationales for the various physical activities chosen.

There were four different physical activity instructors who delivered karate, golf, gymnastics, and playbased activities. All physical activity instructors were asked to deliver content visually and informally, as much as possible. For some activities, such as karate, group visual instruction was effective, whilst for others, such as gymnastics and golf, individual instruction was more effective. Play-based sessions were facilitated by two third-year degree University students, whilst the other instructors were from local community sports clubs and organisations. A major activity rescheduling occurred only once during the program, which was based on participant demand. In week 5, participants (and some of the wider community whom the participants had been discussing the program with) wanted to have a 'sports game day' in a local park, which was accommodated. The sports played on that day were football and volleyball, two of the most commonly played and enjoyed sports in the Karen community.

\section{Educational and discussion modules}


Apart from young children (approximately 8 years and younger), all other participants engaged with the education and discussion modules. The younger children were usually taken aside by non-participant community members to play games, which allowed the adult participants to engage with the educational components. For participants, there was an overwhelming sense of importance for learning about health, PA, and nutrition in Australia. Thus, the educational modules were explicitly requested by the group, and their format and structures were co-designed by them. Because many of the participants were young people or adults who did not have formal education on these topics, the material was aimed at a basic and introductory level. There were language challenges with interpreting technical information, which was clear in instances when the interpreter could not interpret specific words (e.g. 'insulin', 'carbohydrate') due to a lack of directly translatable words. This may have been due to the fact that the Karen language may be regarded as 'nontechnical', and as Larson [34] argues, it may be difficult to translate information originating from a technical source into a nontechnical language. The interpreter would often interpret such words through contextual meaning, and would choose words such as 'sugar' (insulin) or 'rice' (carbohydrate) in order to give meaning to the message. Discussions on Type-II diabetes were specifically chosen because community elders had raised it as a concern in their community prior to program development. This particular health issue was also highlighted as a major health concern by a local General Practitioner (GP) in the area, who worked extensively with the Karen community.

Three educators facilitated the discussion modules; the primary researcher, a research fellow researching Type-II diabetes, and an Australian registered dietician. The primary researcher met with both educators prior to their presentations to discuss their content, appropriate methods of delivery and to highlight several Karen cultural issues that needed to be considered (e.g. focus on verbal rather than written communication, high value for family wellbeing rather than individual, incorporating open discussion as much as possible, and adaptable to community requests).

\section{Evaluations}

Various methods of evaluation were utilised for the program. A semi-ethnographic account of the various aspects of each session was compiled into a journal, and was an amalgamation of events, discussions (informal and formal), observations, and reflections. A brief one-page written response to basic evaluation questions was administered on the final session. A six-month follow up session was held 26 weeks post completion at the same community hub. The session was attended by a researcher, the community leader and 29 participants. The aim of the follow up session was to re-visit opinions regarding the program and participant sport and PA behaviours post program. This was achieved by conducting two group interviews, one with the adults, and one with the children. Whilst one group was being measured and interviewed, the other group were partaking in physical activities (e.g. playing dodgeball, aerobics) in another room. There was no interview schedule for these group interviews, as it was intended to be an informal discussion that was driven by the participants, who were encouraged to discuss matters that were important to them. The researcher only prompted participants to discuss the program (e.g. what participants enjoyed or did not enjoy, if participants could remember anything they 
had learnt), and discuss their sport and PA behaviours since the program (e.g. has more or less activity been done since the program).

\section{Results}

\section{General measurements}

The average measurements of participants taken on the first session of the program and at the six-month follow-up, are provided in Table 2.

Albeit changes in weight were not an outcome of this program, the data collected did suggest that concerns within the local community and service providers about Type-Il diabetes and risk factors such as obesity, were highlighted. The World Health Organization's (WHO) international classification for BMI scores categorise individuals into normal and at-risk ranges which relate to their level of obesity and risks of developing cardiovascular diseases and Type-II diabetes [35]. For both periods of measurement for adult participants, average BMI scores were categorised as being 'overweight' for males and females.

\section{Attendance}

The average attendance of the participation rate over the 8 weeks was $81.8 \%$ with some small variations across the weeks (range 68-93\%). Each week, numerous community members who were not participants attended the sessions and often assisted with minding young children and infants of those who partook in the activities.

\section{Evaluation}

\section{Ethnographic accounts and participant feedback}

Evaluation data was sourced through a collection of researcher observations, informal (e.g. conversations) and formal (e.g. focus groups) participant feedback, and ethnographic documentation. The data suggests that there is an overall sense that all of the participants enjoyed the various sessions, with some variations for certain age groups and participants. Through informal discussions, and observations, it was apparent that most of the participants enjoyed karate; however, the children seemed to enjoy it much more than the adults [26]. The golf clinic was also another activity that children enjoyed a lot more than adults. Gymnastics appeared to be enjoyed by both adults and children equally. Interestingly, it is perceived that the adults enjoyed the play-based sessions more than the children did, particularly based on positive discussions with parents after several play-based sessions. However, the sports game day in the park is the activity that adults and children both enjoyed the most.

In relation to the educational modules, most participants expressed their appreciation for an opportunity to learn about various aspects of health through the educational modules. However, language barriers presented a particularly difficult challenge in delivering the content, despite the presence of an interpreter. The technical concepts (e.g. medical terminology) of some of the material did not translate effectively 
into the Karen language. The interpreter had spent over a decade in Australia at the time of the program, and had engaged with the Australian healthcare system regularly, and as such, was exposed to, and understood such concepts (e.g. insulin). Therefore, she was able to effectively construct meaningful messages using contextual descriptions.

\section{Final evaluation}

There were 28 respondents to the final evaluation; 15 adults and 13 children. It was a requirement that the evaluation questionnaire was co-designed and translated in its final state for the ethics approval of the program, which was obtained well in advance of implementation. Unfortunately, because of this, the questionnaire was not specific about any activities, as they were uncertain at that time. In rating how much participants enjoyed the program overall, 68\% said they 'really enjoyed it' and $32 \%$ said they 'enjoyed it'. Participants mostly felt happy at the conclusion of the 8-week program (93\%). The part of the program that respondents enjoyed the most was the physical activities, followed by the educational modules, and then the social aspects [26]. Figure 2 presents the responses to what participants thought were the best things about being involved in the intervention, of which having fun with others in the community was the most frequent response.

According to $75 \%$ of respondents, the program met their expectations, with $7 \%$ saying that it delivered more than expected. Only one respondent (a 10-year-old child) said they did not like 'the lectures', whilst all other respondents said there was nothing in the program they did not like. Almost $95 \%$ of the respondents stated they would like to be involved in a similar program in the future, with some participants writing they 'loved this program' and they 'wish to have another opportunity like this in the future' [26].

Interviews and informal discussions with physical activity instructors were also generally positive. The karate instructors in particular were grateful to have had an opportunity to volunteer their skills to assist the community. They also expressed that they felt they had 'gained a lot' from the experience in terms of coaching individuals who were not comprehensive in the English language. The combination of age and skill levels in the class was not a barrier, as this was something that they were used to doing regularly with family classes. For the gymnastics coaches, however, they identified this to be a challenge. Normally, gymnastics sessions are categorised based on ages due to varying degrees of physical skill levels, thus the very young children struggled with some movements (e.g. balancing). However, all instructors were positive about delivering their sessions in a challenging environment, agreeing that it assisted them with being innovative and adaptive to the community, and that the program proved that 'this is something that could be done in the future'.

\section{Six-Month Follow Up}

The results of the group interviews suggested that all participants valued the program, particularly for its focus on PA and involvement of their whole family. However, the majority of adults were less physically active after the program than they were before it, with only one participant in the group stating that she 
was more physically active by walking regularly. In discussing this, some participants said that the weather had been too cold after the program; others said they got jobs and no longer needed to cycle to the English classes or walk their children to school as often. When asked what they could remember doing and learning in the program, both adults and children could remember and recount the sport and physical activities. No participant discussed the educational material. The most discussed activity was karate, particularly with the children [26]. In response to whether participants disliked any aspects of the program, one adult participant stated "No. This is the first time in our whole community that we have ever had a program for exercise, that someone organised for us, so, it's really good for us" (Female adult participant) [26]. None of the participants had used the equipment that was left at the community hub; however, they did use the volleyball net regularly. The volleyball net was stored at a local church where many Karen were members, and it was used freely on a loan basis by the whole community. Adults and children both expressed their gratitude for the donation and mentioned that it was 'used all the time'. The community leader managed the use of the net as she was a very active and well-known member of the community and knew most of the Karen families, allowing her to organise the loan and whereabouts of the net. During a project conclusion meeting with the interpreter, she mentioned that her community had never had something this important donated to them, because volleyball was loved by everyone in the community. She continued to say that it provided an opportunity for the adults and the older people to teach the youth about the Karen culture and 'how we played back home' [26].

\section{Discussion}

This co-designed funded program addressed socio-cultural constraints and needs, values, beliefs and accessibility barriers. The perceived effectiveness of the program was in-part due to the underpinning work through research and relationship building with refugee background Karen community members, that specifically reflected the needs and voices of the broader group. The adults and the children responded differently to the various activities. Although the golf activity was requested by the parents, it was the children who seemed to enjoy it more than the adults, perhaps because it was set up to appeal to children with lots of brightly coloured equipment and a moving target. This finding signifies the importance of considering the correlates of PA, such as age, type, and context of PA interventions. Adults responded positively to gymnastics, possibly because it allowed them to explore and test their physical abilities in an entirely new fashion and skill learning. Unlike karate, which was also a new activity for them, it involved more than utilising basic skills which were within the usual normal movements one performs (e.g. extending arms into a punch). Gymnastics involved tumbling, balancing, cartwheeling, rolling, crawling, and jumping, which the adults all seemed to enjoy trying to master. Interestingly, adults appeared to enjoy the play-based activities more than the children did. This may be because children would have already played most of the games in school (e.g. fruit salad), whereas the adults were learning games they had never experienced before, and genuinely enjoyed [26]. In their study on family play activities, Coyl-Shepherd and Hanlon [36] found that parents reported genuinely enjoying play-based

activities, and sharing interests with their children, whilst recognizing these opportunities would be limited as the children grew older. Throughout the program, both adults and children seemed to enjoy playing 
with each other, especially in team based competitive games like races. However, it was clear that the sports game day in the park was one of the most enjoyed sessions, with many participants bringing food (even though snacks were provided), and assisting in setting up volleyball and football spaces by erecting nets, assembling goals, inflating balls and marking play areas with cones. Participants were not placed into teams; they naturally gathered around the sport they wished to play. Most children (of approximately 13 years old and younger) chose football, whilst the majority of young people and adults chose volleyball. The sports game day activity allowed participants to socialise and work together to create and set-up, involve others in their community group, and partake in an activity that was familiar and valued. It also allowed the participants to showcase these characteristics, along with other cultural practices (e.g. food) to the researchers; something the group felt proud to do. The session most resembled PA that is familiar in the way it was done pre-migration to Australia; games were played according to their own rules, terms and methods, in an open and public space, through inclusive sharing, connecting, and socialising. For the program as a whole, there were several benefits, as well as limitations and barriers, which serve as learning points for practitioners in this field.

\section{Benefits}

\section{Practical outcomes}

From a practical perspective, the program provided an opportunity for participants to try new activities and learn about various health related topics in a valuable and meaningful way. An initiative by Mohammadi [37] targeting newly arrived female asylum seekers and refugees highlighted how needsbased, informal and intercultural provisions within their program, created opportunities for participants to acquire the necessary physical capital to partake in biking in a new country (Germany). Similarly, our program provided the participants with opportunities to broaden their physical skill capabilities, whilst building confidence in their abilities to engage in new and potentially intimidating activities in a new country. An example of this was golf, which was specifically requested by participants because it was perceived as being an activity that was 'shown on TV and inaccessible for Karen communities' (based on our previous research). Participants were provided with an opportunity to learn some of the basic movements and rules of the game, whilst also acquiring new skills and interests in an activity often regarded as 'inaccessible' due to high costs of membership and perception of the sport being 'elite'. Another outcome was the positive associations participants had built with the community hub and the staff, which was significant for the hub coordinators. This particular group were identified as 'hard to reach' for the local government who managed the hub, and had limited engagement with the local Karen community. Participants became comfortable with the services available at the hub, using the facilities, and had built a relationship with hub staff, and eventually built a sense of ownership of the hub. As the program progressed, participants were more comfortable in their environment, and more confident in their understanding of the purpose of the program. Rather than gathering in a group and waiting for facilitators to instruct them, the participants started going into the storeroom to assist with setting up or play with the equipment, they laid out the foam mats, they brought food and made tea and coffees, they socialised before, during, and after the activities. This was a stark contrast from individuals who had 
never set foot in the hub before, with some who were not even aware of its existence, despite the centre's location (within walking distance from most participants) [26].

The program also provided a starting point upon which other culturally specific programs were developed and open to the broader community (e.g. Tai Chi, Bollywood dancing) at the community hub, of which many local Karen individuals participated in.

\section{Relationships and collaborations}

The physical activity instructors identified a range of benefits from the program, specifically, having an opportunity to learnt to adapt their practices in a challenging setting. For the gymnastics instructors in particular, the program's requirement to engage all different age groups was challenging. However, they expressed that they would not have had an opportunity to develop novel strategies to deliver the activities effectively in a standard environment. The instructors also built capacities to engage positively, and effectively, with culturally diverse communities. Moreover, participant engagement with the physical activity instructors was overall a positive experience, with most instructors being approachable, helpful and fun. For participants, this experience may lead to the creation of positive relationships which could influence their perspectives of sport opportunities in Australia, and potentially create prospects for participation in the future. A collaborative relationship between the University and the local government body was also strengthened, and eventuated into involvement of student projects and placements with future community programs in the area.

\section{Facilitators}

One of the key facilitators to the program was the collaborative and co-designed approach, which formed the structure, content and the maintenance of the program. Community engagement and input from conception through to implementation and evaluation, was central to delivering an appropriate and meaningful program. Through a well-developed understanding of the group, the program's outputs reflected the participants' specific values and needs, whilst addressing common barriers for participation. Participation rates remained high throughout the program, and got higher towards the end (see Figure 1).

\section{Barriers and limitations}

Language and cultural barriers were the key limitations to this program. Relying on the community leader to translate and interpret interactions with up to 36 individuals at a time during educational and physical activity sessions was problematic. During the planning phases of the intervention, the research team did discuss working with another Karen interpreter. However, the community leader insisted that adding a new person to the already existing and well-known researcher and community leader duo would confuse the community and make participants feel shy or reserved [26]. In an ideal situation, it would be most appropriate for the program to be facilitated by someone who is fluent in the target group's language. Unfortunately, this was not possible in our case. Still, a little over half of the participants were children, who understood English and were able to assist with overcoming some language barriers. For example, 
some of the children were chosen to assist with snack preparation. During this time, the researcher conversed with them about what their parents thought about the program, what activities they enjoyed, and what they wanted to learn more about. Moreover, some of the children and young adults acted as interpreters within their activity groups naturally, and often spoke to the instructors on the group's behalf. Due to the language barriers, the play-based activities were inherently challenging to deliver. Each week the activities were different, and participants were required to learn several new games each session. As the activities were based on games, there was usually a set of rules or boundaries that needed to be verbally communicated rather than visually demonstrated. For activities such as karate, golf, and gymnastics, visual demonstration worked effectively, particularly when participants could observe what other participants were doing and mimic the movements. In many of the play-based games, for example fruit salad (individuals are assigned a fruit and when called out, must sprint from one end of the room to the other); it was essential for participants to understand the objectives of the game in order to participate adhering to the rules of the game [26].

Language barriers were a particularly difficult challenge in delivering the educational modules, and although this was mediated by the interpreter, developing resources that convey technical information to young audiences could be an effective strategy to overcome this challenge. For example, using visual representations, such as animated videos, to depict what a rise in blood sugar may look like and how it affects the body. This program also highlighted how the current curriculum for dieticians may not effectively equip them with the skills to work in culturally diverse community settings in a sensitive and appropriate manner. Stronger attention to equipping professionals to deliver highly technical information that is targeted and sensitive to the group's cultural and individual dietary needs, should be considered in implementing programs such as ours. This challenge was highlighted in our case by the material which focused heavily on the Australian nutritional guidelines, and carbohydrates in particular. The discussion of how much carbohydrate (translated as 'rice') should be consumed daily, was somewhat shocking for participants. Rice is a staple in the Karen diet, which is often consumed for breakfast, lunch, and dinner.

\section{Sustainability}

A lack of sustainable outcomes of the program was a limitation. Despite numerous considerations for sustainability (e.g. strategic collaborations with community sporting organisations and groups, play equipment donated to the hub for continued use, comfort with accessing the hub and voicing needs to hub staff), there was limited sustainability. Albeit some participants (particularly the young people) engaged with the hub post-program through a variety of different capacities and programs (e.g. volunteering, participation in physical activity programs), over time, Karen community engagement with the hub dropped off. The equipment was not used on a loan basis as anticipated. The equipment was utilised during the intervention every week, and thus it was assumed that participants would feel comfortable with, and find enjoyment in using it, post-program. However, none of the participants used the equipment post completion of the program, and some said that they did not know they were allowed to use it. 
The limited sustainability pathways could be due to a variety of reasons. There may have been a lack of funding to deliver culturally specific and exclusive programs catering solely to Karen needs, or, administrative processes (e.g. to 'loan' the equipment or book a space at the hub) may have been too intimidating or difficult to navigate. Utilising the community hub's equipment may have been perceived as too procedural, or that processes to obtain the equipment were time consuming as users were required to visit the centre during working hours and complete and sign a loan ledger. Although participants were verbally instructed how to loan the equipment, a practical 'run through' of how that process worked, was not provided. On the other hand, the volleyball net that was donated to the community leader was used regularly, and its use was managed informally through individuals contacting each other. Thus, one of the biggest contributors to their lack of engagement with the hub, however, may have been simply, that the group just preferred to engage in physical activity that is most familiar and comfortable to them, such as casual sports and informal play at the local parks.

\section{Program design and future recommendations}

Several recommendations for future programs and research evolved from the development, implementation, and evaluation outcomes of this feasibility program. Albeit these recommendations are offered for potential transferability, even similar programs that are implemented will be unique in their environment, target groups, collaborators and a host of various other factors. It is imperative that program facilitators and researchers apply a specific approach to their needs, to increase effectiveness and appropriateness of programs [19].

To begin with, it is important to have a good understanding of the target group's culture, needs, and contexts, before developing and implementing projects similar to this program. It is crucial to understand how CALD individuals see and experience the world, especially in relation to how they define and value certain concepts such as health, sport, and PA. In this project, prior research results provided this understanding, and ultimately led to the co-design and development of this culturally specific program. It is important to also understand the culturally specific barriers and facilitators to participation, in order to develop program parameters accordingly. For example, the Karen are highly collectivist and family time is highly valued, which led to the creation of a family-centred program. The co-design approach was another essential component of this intervention. Adopting a community participatory approach provides decision-making power to the groups that the facilitators aim to support [29]. Empowering communities to deliver input into the program may also give them a sense of ownership and belonging, which in turn would make the program more effective and significant for the group. If a co-design approach cannot be utilised, a strategy would be to recruit potential participants, or willing advisory groups, well before the logistical confirmation of the program, and allow the group to provide feedback and discuss potential issues with implementation regularly over the course of program development.

For researchers and facilitators who are new to the group's culture and who may need to overcome language barriers, it is important to work with individuals who can be cultural advisors, interpreters, community links, and partners, to be able to access this information [26]. Providing a culturally specific 
program ensures that participants gain valuable and significant outcomes for themselves and their families. Thus, participants will be motivated to attend regularly and engage on a meaningful level by asking questions, feeling comfortable, and maintaining interest for future engagement

Another recommendation is to create working partnerships and collaborative arrangements. Albeit this is not a new concept, the importance of it must be stressed. Having a wide partnership network when endeavouring to implement a community-based program would add to the program's effectiveness, reach, meaningfulness, and sustainability. Program collaborates not only offer in-kind support and resources, but also expertise that the program team may not have (e.g. gymnastics coaches who modified movements to suit varying age and skill levels of participants) [26].

Moreover, our program was intentionally created to be flexible and evolving due to the constant feedback from, and involvement of, the participants in delivering the program. The Karen community often voiced that they did not know what type of activities they would like to play because they were unfamiliar with sports and recreational physical activities in Australia, as well as, the Australian nutritional advice. Therefore, the program needed to be flexible enough to adapt and change according to their response to the education materials or the activities. In order to achieve this, it is important to commit to flexibility early on in the program development. This fosters the idea of evolving the program as it goes along, and this idea needs to be at the heart of all program planning. The key in achieving a truly flexible program that is reactive and adaptive to a vast array of community requests, is preparation. Facilitators could be more prepared by developing a 'skeleton' program (e.g. broad and general ideas of the direction of the program) and having multiple sets of options, which can slot into the skeleton and fill in the blanks as the program progresses [26]. It is also important to be comfortable and open to the notion of making changes throughout the entire program, and this is effectively achieved by having a large bank of contacts, educators, instructors, assistants, alternate locations, equipment; all of which can be called upon promptly if required. A comfortable and safe space also needs to be created for the participants to feel that they can be open to make requests and suggest changes to suit their needs during any phase of development or implementation.

In summary, one of the most important research recommendations is the need for more tailored and appropriate evaluation methods. Our program piloted various methods of evaluation, which showed that some were more effective than others. Thus, a more culturally specific and meaningful evaluation approach would be more effective and efficient in future studies. A more effective and appropriate evaluation strategy would have been to employ, and culturally tailor, a more substantial approach, such as the RE-AIM framework [38]. This particular framework is designed to assess the significance of public health interventions [38], and is frequently used to evaluate nutritional and PA interventions [e.g. 39, 40, 41]. This approach, tailored to the target group and the program characteristics, would have been particularly useful for the current study, where a close working relationship with local government may have assisted with future policy changes or implementations, potentially bridging the divide between research and practice. However, it is acknowledged that Western developed frameworks, such as the RE- 
AIM method of evaluation, may be inappropriate or ineffective to implement in a culturally and linguistically diverse setting, where values and meaning may differ to the key concepts of the framework.

\section{Conclusions}

The program was designed to increase PA participation in the Karen community over the duration of the program, provide families with an opportunity to be active together, and try new activities for the first time. In general, it was successful in doing so. Most participants attended the sessions regularly and participated in all activities together. The various forms of evaluation suggested that all participants enjoyed the program, particularly the sport and PA components of it, and would like to partake in similar activities in the future. The program provided a comfortable, safe space for Karen families to participate in PA in ways that were meaningful and valuable to them.

Thus, our study suggests that culturally specific sport and PA programs can be effective in engaging refugees in active lifestyle behaviours in their settled countries. Building the program on the foundations of a strong cultural understanding, commitment to meaning for the group, and forward thinking in sustainability, are key elements in creating a robust and effective program.

\section{List Of Abbreviations}

$\mathrm{BMI}$ - Body mass index

CALD - Culturally and linguistically diverse

PA - Physical activity

PTSD - Posttraumatic stress disorder

WHR - Waist to hip ratio

\section{Declarations}

\section{Ethics approval and consent to participate}

Ethics approval was granted by the Victoria University Human Research Ethics Committee (VUHREC) (ID: HRE14-036) in 2014. The authors confirm that the study (methods, reporting and communication, etc.) was conducted in accordance with all relevant guidelines and regulations as specified in the ethics approval documentation. Informed consent was obtained from all participants involved. Parents and/or guardians of participants who were under the age of 18 years provided consent.

\section{Consent for publication}

This manuscript has not reported on any identifiable individual's data. 
Availability of data and materials

The data used and analysed in this manuscript are not publicly available to due privacy and confidentiality of participants involved in the studies (including prior research involving the same participants, not reported in this manuscript). The corresponding author has access to the dataset, which can be de-identified and shared on reasonable request.

\section{Competing interests}

The authors declare that they have no competing interests.

\section{Funding}

The program was entirely funded by South Western Melbourne Medicare Local (SWMML) through the 'Local Community Grant (Laverton and Laverton North' funding round. A total of AUD\$13,900 was awarded. The funding body was not involved in any aspect pertaining to the research, including design of the study or data collection, data analysis and interpretation of data, and drafting or editing the manuscript.

\section{Authors' contributions}

TO'D, EB and RP all conceived of the study and developed the program and logistics together. TO'D was the main researcher and facilitator of the program, whilst EB and RP assisted with interpretation of results. EB and RP also assisted with major sessions of the program, such as the graduation day. TO'D and RS drafted the initial manuscript, whilst EB and RP provided significant contributions and comprehensive editing to the final manuscript. All authors have read, and approved the final manuscript.

\section{Acknowledgements}

Not applicable.

\section{References}

1. Carless D, Douglas K: Sport and Physical Activity for Mental Health: Wiley; 2011.

2. Hardman AE, Stensel DJ: Physical Activity and Health: The Evidence Explained, 2nd edn: Routledge; 2009.

3. Warburton DE, Nicol CW, Bredin SS: Health benefits of physical activity: the evidence. CMAJ 2006, 174(6):801-809.

4. Eime R, Harvey J, Charity MJ, Casey M, Van Uffelen J, Payne WJBph: The contribution of sport participation to overall health enhancing physical activity levels in Australia: a population-based study. 2015, 15(1):806. 
5. Kim ACH, Park SH, Kim S, Fontes-Comber AJA, Society: Psychological and social outcomes of sport participation for older adults: A systematic review. 2020, 40(7):1529-1549.

6. Mandolesi L, Polverino A, Montuori S, Foti F, Ferraioli G, Sorrentino P, Sorrentino GJFip: Effects of physical exercise on cognitive functioning and wellbeing: biological and psychological benefits. 2018, 9:509.

7. Nathan S, Kemp L, Bunde-Birouste A, MacKenzie J, Evers C, Shwe TA: "We wouldn't of made friends if we didn't come to Football United": the impacts of a football program on young people's peer, prosocial and cross-cultural relationships. BMC Public Health 2013, 13(1):399.

8. Super S, Hermens N, Verkooijen K, Koelen MJBph: Examining the relationship between sports participation and youth developmental outcomes for socially vulnerable youth. BMC Public Health 2018, 18(1):1012.

9. Australian Bureau of Statistics: Participation in Sport and Physical Recreation, Australia, 2011-12. In. Canberra, Australia: Commonwealth of Australia; 2012.

10. Australian Bureau of Statistics: National Health Survey: First Results, 2017-18. In. Canberra, Australia: Australian Government; 2018.

11. Caperchione CM, Kolt GS, Mummery WK: Physical Activity in Culturally and Linguistically Diverse Migrant Groups to Western Society: A Review of Barriers, Enablers and Experiences. Sports Medicine 2009, 39(3):167-177.

12. Caperchione CM, Kolt GS, Tennent R, Mummery WK: Physical activity behaviours of Culturally and Linguistically Diverse (CALD) women living in Australia: A qualitative study of socio-cultural influences. BMC Public Health 2011, 11(1):1-10.

13. Wieland ML, Tiedje K, Meiers SJ, Mohamed AA, Formea CM, Ridgeway JL, Asiedu GB, Boyum G, Weis JA, Nigon JA: Perspectives on Physical Activity Among Immigrants and Refugees to a Small Urban Community in Minnesota. $J$ Immigr Minor Health 2013:1-13.

14. Horne M, Tierney S: What are the barriers and facilitators to exercise and physical activity uptake and adherence among South Asian older adults: a systematic review of qualitative studies. Prev Med 2012, 55(4):276-284.

15. Berry JW, Poortinga YH, Breugelmans SM, Chasiotis A, Sam DL: Cross-cultural psychology: Research and applications, 3rd edn. Cambridge, UK: Cambridge University Press; 2011.

16. Berry JW: Acculturation. In: Culture and Human Development: The Importance of Cross-Cultural Research to the Social Sciences. edn. Edited by Friedlmeier W, Chakkarath P, Schwarz B. New York: Psychology Press; 2005: 291-302.

17. Gerber M, Barker D, Pühse U: Acculturation and physical activity among immigrants: a systematic review. Journal of Public Health 2011, 20(3):313-341.

18. Taylor T, Toohey K: Behind the veil: Exploring the recreation needs of Muslim women. Leisure 2001, 26:85-105.

19. Caperchione CM, Kolt GS, Mummery WK: Examining physical activity service provision to culturally and linguistically diverse (CALD) communities in Australia: a qualitative evaluation. PloS one 2013, 
8(4):e62777.

20. Hashimoto-Govindasamy L, Rose V: An ethnographic process evaluation of a community support program with Sudanese refugee women in western Sydney. Health Promot J Austr 2011, 22(2):107112.

21. Ley C, Barrio MR: Promoting health of refugees in and through sport and physical activity: a psychosocial, trauma-sensitive approach. In: An Uncertain Safety. edn.: Springer; 2019: 301-343.

22. Dinas $\mathrm{P}$, Koutedakis Y, Flouris A: Effects of exercise and physical activity on depression. Ir J Med Sci 2011, 180(2):319-325.

23. Josefsson T, Lindwall M, Archer T: Physical exercise intervention in depressive disorders: Metaanalysis and systematic review. Scand J Med Sci Sports 2014, 24(2):259-272.

24. Nilsson H, Saboonchi F, Gustavsson C, Malm A, Gottvall M: Trauma-afflicted refugees' experiences of participating in physical activity and exercise treatment: a qualitative study based on focus group discussions. European Journal of Psychotraumatology 2019, 10(1):1699327.

25. Robinson DB, Robinson IM, Currie V, Hall N: The Syrian Canadian sports club: a community-based participatory action research project with/for Syrian youth refugees. Social Sciences 2019, 8(6):163.

26. O'Driscoll T: Exploring cultural variables affecting sport and physical activity behaviours of Karen refugees in Australia: applying a culturally specific approach to active lifestyles. Melbourne, Australia: Victoria University; 2016.

27. Haggis C, Sims-Gould J, Winters M, Gutteridge K, McKay HA: Sustained impact of community-based physical activity interventions: key elements for success. BMC Public Health 2013, 13(1):892.

28. Sanders EBN, Stappers PJ: Co-creation and the new landscapes of design. CoDesign 2008, 4(1):5-18.

29. Greenhalgh T, Jackson C, Shaw S, Janamian T: Achieving Research Impact Through Co-creation in Community-Based Health Services: Literature Review and Case Study. 2016, 94(2):392-429.

30. Leask CF, Sandlund M, Skelton DA, Chastin SFJHej: Co-creating a tailored public health intervention to reduce older adults' sedentary behaviour. 2017, 76(5):595-608.

31. McKay H, Nettlefold L, Bauman A, Hoy C, Gray SM, Lau E, Sims-Gould J: Implementation of a codesigned physical activity program for older adults: positive impact when delivered at scale. $B M C$ Public Health 2018, 18(1):1289.

32. Albright CL, Pruitt L, Castro C, Gonzalez A, Woo S, King AC: Modifying physical activity in a multiethnic sample of low-income women: one-year results from the IMPACT (Increasing Motivation for Physical ACTivity) project. Annals Of Behavioral Medicine: A Publication Of The Society Of Behavioral Medicine 2005, 30(3):191-200.

33. Borschmann K, Moore K, Russell M, Ledgerwood K, Renehan E, Lin X, Brown C, Sison J: Overcoming barriers to physical activity among culturally and linguistically diverse older adults: a randomised controlled trial. Australas J Ageing 2010, 29(2):77-80.

34. Larson ML: Meaning-based translation: a guide to cross-language equivalence, 2nd edn. New York, NY: University Press of America; 1998. 
35. World Health Organization: Global Database on Body Mass Index. In: BMI Classification. 2006 edn. Geneva: World Health Organization; 2006.

36. Coyl-Shepherd DD, Hanlon C: Family play and leisure activities: correlates of parents' and children's socio-emotional well-being. International Journal of Play 2013, 2(3):254-272.

37. Mohammadi S: Social inclusion of newly arrived female asylum seekers and refugees through a community sport initiative: the case of Bike Bridge. Sport in Society 2019, 22(6):1082-1099.

38. Glasgow RE, Vogt TM, Boles SM: Evaluating the public health impact of health promotion interventions: the RE-AIM framework. Am J Public Health 1999, 89(9):1322-1327.

39. Caperchione CM, Duncan M, Kolt GS, Vandelanotte C, Rosenkranz RR, Maeder A, Noakes M, Karunanithi M, Mummery WK: Examining an Australian physical activity and nutrition intervention using RE-AIM. Health promotion internationa/2015, 1:9.

40. Van Acker R, De Bourdeaudhuij I, De Cocker K, Klesges LM, Cardon G: The impact of disseminating the whole-community project '10,000 Steps': a RE-AlM analysis. BMC Public Health 2011, 11:3.

41. Estabrooks PA, Bradshaw M, Dzewaltowski DA, Smith-Ray RL: Determining the impact of Walk Kansas: applying a team-building approach to community physical activity promotion. Ann Behav Med 2008, 36(1):1-12.

\section{Tables}

Table 1 Activity rationalisation 


\begin{tabular}{|c|c|c|}
\hline Activity & Incentive & Other Contributing Factors \\
\hline Karate & $\begin{array}{l}\text { Example of new activity agreed upon during } \\
\text { prior focus groups }\end{array}$ & $\begin{array}{l}\text { Local karate group already } \\
\text { operating from the community } \\
\text { centre }\end{array}$ \\
\hline Golf Clinic & $\begin{array}{l}\text { Raised by previous research participants as an } \\
\text { activity they would like to try }\end{array}$ & $\begin{array}{l}\text { Local clubs keen to engage } \\
\text { groups like Karen and adopt a } \\
\text { more inclusive approach }\end{array}$ \\
\hline Gymnastics & $\begin{array}{l}\text { Discussions with Gymnastics Victoria (GV) and } \\
\text { Gymnastics Australia (GA) revealed they are } \\
\text { increasingly focusing on inclusive approaches } \\
\text { and initiatives targeting CALD communities }\end{array}$ & $\begin{array}{l}\text { Previous research participants } \\
\text { suggested that gymnastics was a } \\
\text { sport only for 'Australian kids' }\end{array}$ \\
\hline Football & $\begin{array}{l}\text { Community members specifically requested } \\
\text { football }\end{array}$ & $\begin{array}{l}\text { One of the most popular and } \\
\text { common sports in Karen } \\
\text { communities; football is familiar } \\
\text { and comfortable. }\end{array}$ \\
\hline Volleyball & $\begin{array}{l}\text { Community members specifically requested } \\
\text { volleyball }\end{array}$ & $\begin{array}{l}\text { One of the most popular and } \\
\text { common sports in Karen } \\
\text { communities; volleyball is familiar } \\
\text { and comfortable. }\end{array}$ \\
\hline Play Based & $\begin{array}{l}\text { Specifically addresses key issue of previous } \\
\text { research; perceived time barriers due to child } \\
\text { minding and caregiving roles }\end{array}$ & $\begin{array}{l}\text { Opportunity for Karen participants } \\
\text { to learn how to be active together } \\
\text { with their children by playing } \\
\text { games and age-inclusive activities }\end{array}$ \\
\hline
\end{tabular}

Table 2 Average participant measurements 


\section{Week 1}

\begin{tabular}{|c|c|c|c|c|}
\hline & \multicolumn{2}{|l|}{ Children } & \multicolumn{2}{|l|}{ Adults } \\
\hline & Males & Females & Males & Females \\
\hline Height & $\begin{array}{l}1.27 m \\
(n=8)\end{array}$ & $\begin{array}{l}1.33 m \\
(n=11)\end{array}$ & $\begin{array}{l}1.63 m \\
(n=4)\end{array}$ & $\begin{array}{l}1.53 m \\
(n=13)\end{array}$ \\
\hline Weight & $\begin{array}{l}33 \mathrm{~kg} \\
(\mathrm{n}=8)\end{array}$ & $\begin{array}{l}36.5 \\
(n=11)\end{array}$ & $\begin{array}{l}73.1 \mathrm{~kg} \\
(\mathrm{n}=4)\end{array}$ & $\begin{array}{l}60.2 \mathrm{~kg} \\
(\mathrm{n}=13)\end{array}$ \\
\hline BMI & $\begin{array}{l}19.4 \\
(n=8)\end{array}$ & $\begin{array}{l}19.9 \\
(n=11)\end{array}$ & $\begin{array}{l}27.4 \\
(n=4)\end{array}$ & $\begin{array}{l}25.6 \\
(n=13)\end{array}$ \\
\hline WHR & $\begin{array}{l}0.88 \\
(n=7)\end{array}$ & $\begin{array}{l}0.80 \\
(n=9)\end{array}$ & $\begin{array}{l}0.88 \\
(n=4)\end{array}$ & $\begin{array}{l}0.85 \\
(n=12)\end{array}$ \\
\hline Plank & $\begin{array}{l}102 \text { seconds } \\
(n=4)\end{array}$ & $\begin{array}{l}106 \text { seconds } \\
(n=6)\end{array}$ & $\begin{array}{l}84 \text { seconds } \\
(n=3)\end{array}$ & $\begin{array}{l}61 \text { seconds } \\
(n=10)\end{array}$ \\
\hline \multicolumn{5}{|c|}{6 Month Follow Up } \\
\hline & Children & & Adults & \\
\hline & Males & Females & Males & Females \\
\hline Height & $\begin{array}{l}1.24 m \\
(n=7)\end{array}$ & $\begin{array}{l}1.34 m \\
(n=11)\end{array}$ & $\begin{array}{l}1.63 m \\
(n=4)\end{array}$ & $\begin{array}{l}1.53 m \\
(n=13)\end{array}$ \\
\hline Weight & $\begin{array}{l}32 \mathrm{~kg} \\
(\mathrm{n}=6)\end{array}$ & $\begin{array}{l}42 \mathrm{~kg} \\
(\mathrm{n}=9)\end{array}$ & $\begin{array}{l}72.4 \mathrm{~kg} \\
(\mathrm{n}=3)\end{array}$ & $\begin{array}{l}61.3 \mathrm{~kg} \\
(\mathrm{n}=10)\end{array}$ \\
\hline BMI & $\begin{array}{l}21.1 \\
(n=6)\end{array}$ & $\begin{array}{l}21.9 \\
(n=9)\end{array}$ & $\begin{array}{l}26.8 \\
(n=3)\end{array}$ & $\begin{array}{l}26.5 \\
(n=10)\end{array}$ \\
\hline WHR & $\begin{array}{l}0.89 \\
(n=6)\end{array}$ & $\begin{array}{l}0.81 \\
(n=10)\end{array}$ & $\begin{array}{l}0.95 \\
(n=3)\end{array}$ & $\begin{array}{l}0.86 \\
(n=10)\end{array}$ \\
\hline Plank & N/A & $\mathrm{N} / \mathrm{A}$ & $\begin{array}{l}35 \text { seconds } \\
(n=1)\end{array}$ & $\begin{array}{l}40 \text { seconds } \\
(n=8)\end{array}$ \\
\hline
\end{tabular}




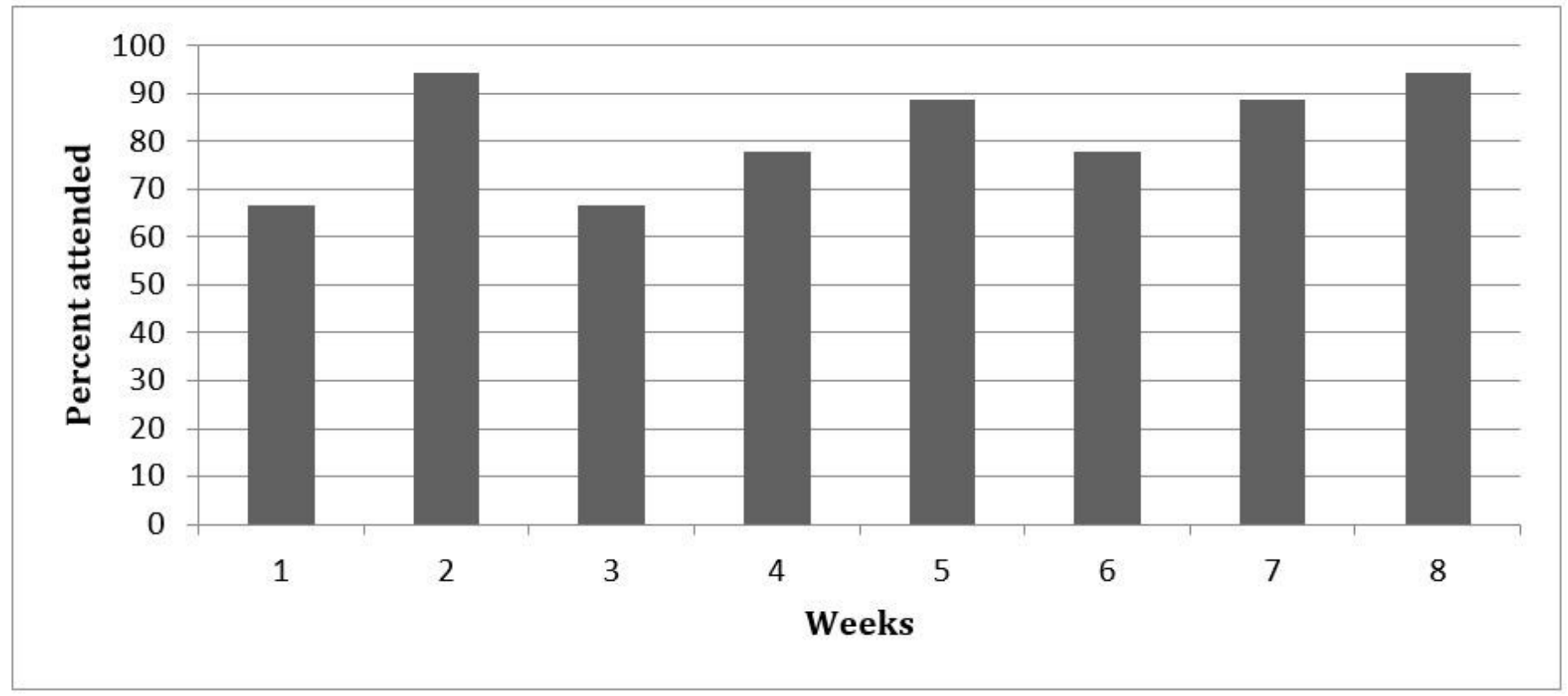

Figure 1

Weekly attendance percentages

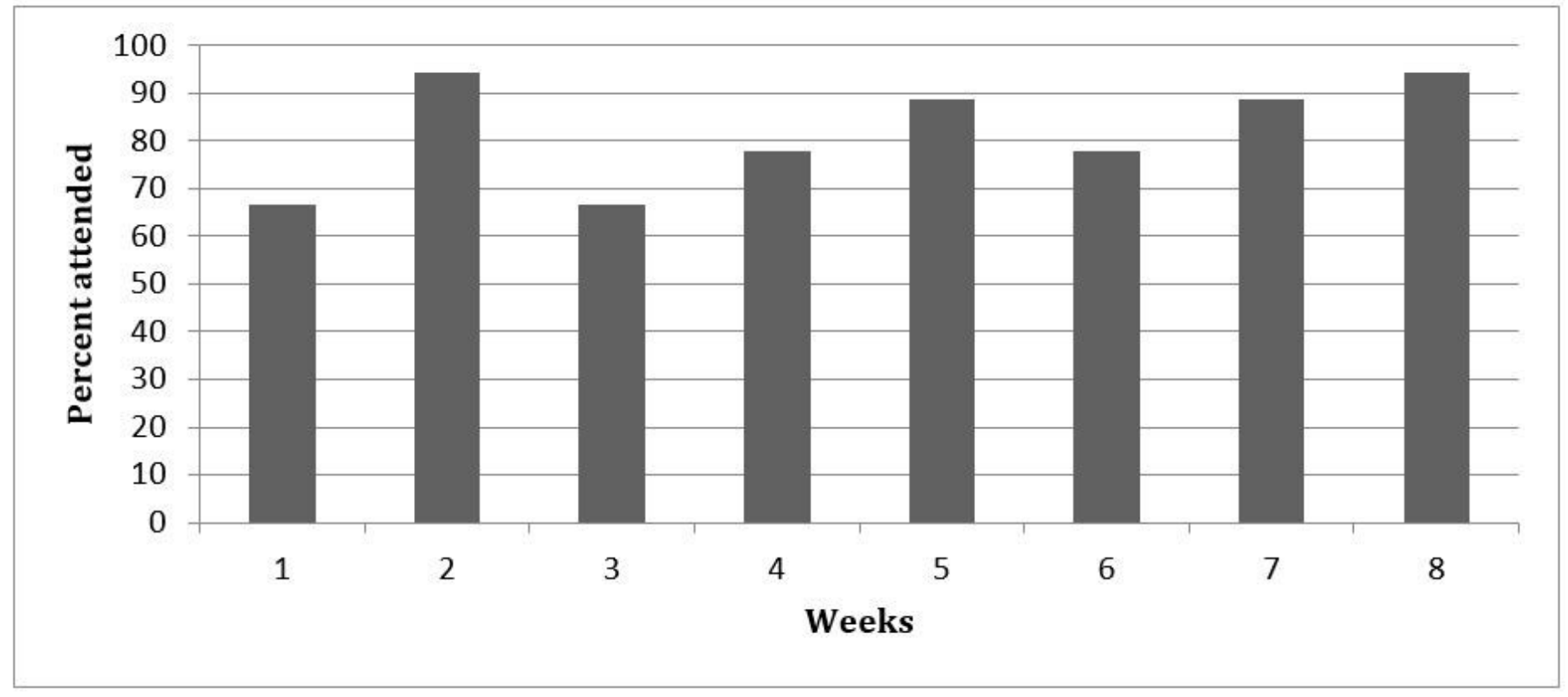

Figure 1

Weekly attendance percentages 
What were the best things about being in this program?

Children Adults

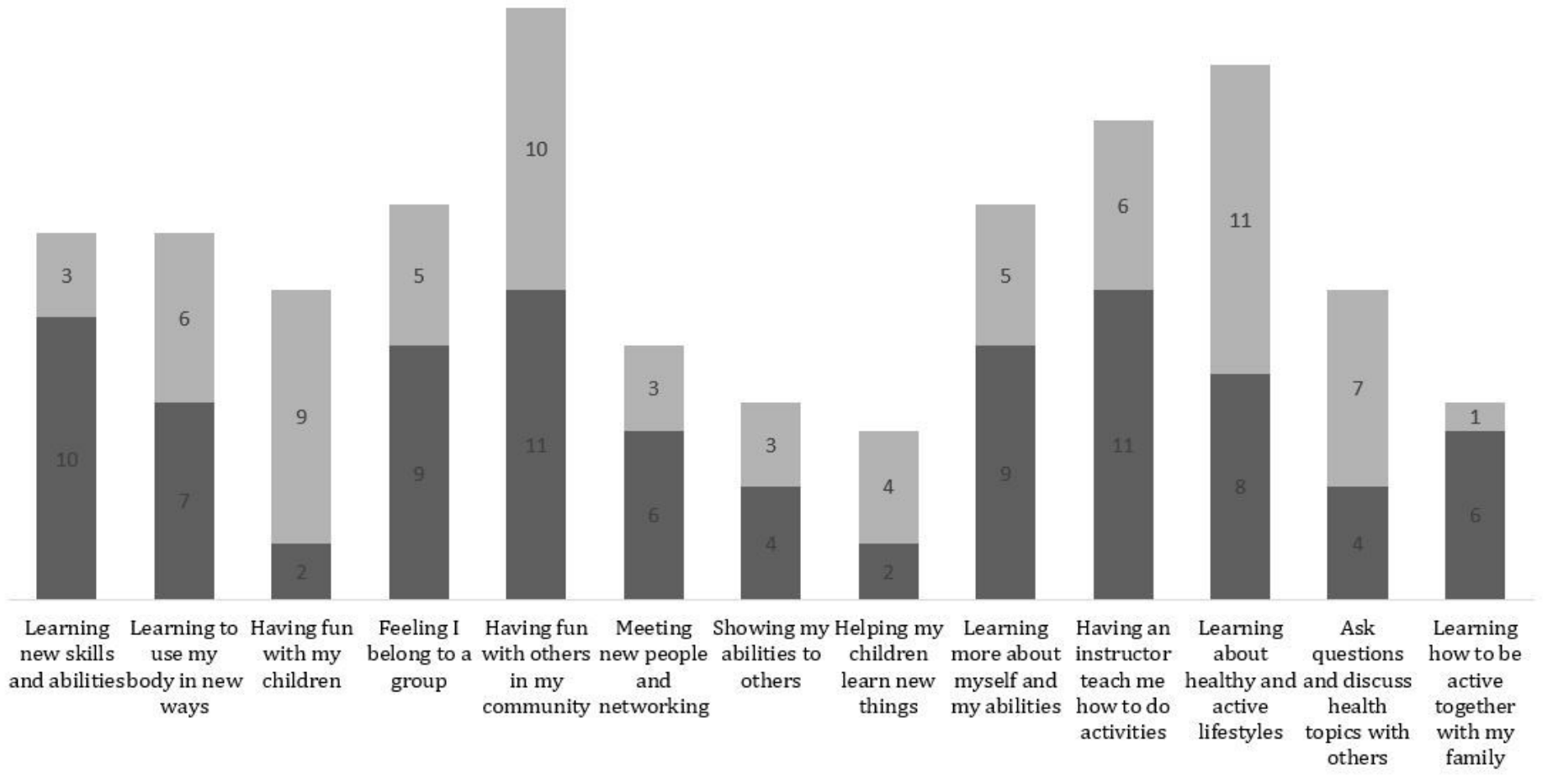

Figure 2

Reponses to the best aspects of the intervention 


\section{What were the best things about being in this program?}

Children Adults

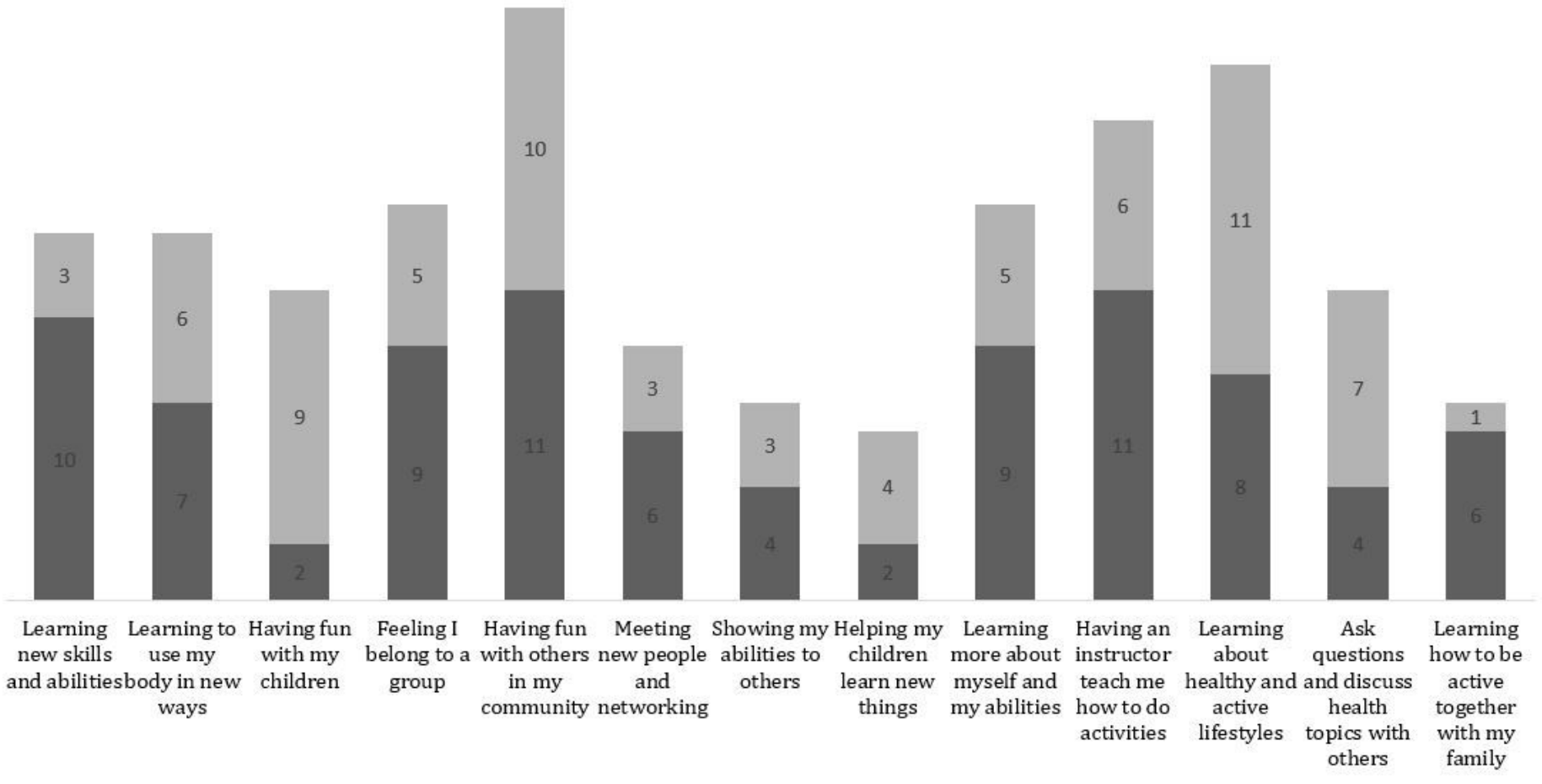

Figure 2

Reponses to the best aspects of the intervention 